\title{
Aspects about the implementation of the occupational safety and health strategy in Romania
}

\author{
Nicoleta Paula Neag $^{1, *}$, and Alin Gaureanu ${ }^{1}$ \\ ${ }^{1}$ Politehnica University of Timisoara, Faculty of Management in Production and Transportation, 14 \\ Remus street, 300191 Timisoara, Romania
}

\begin{abstract}
European directives related the occupational health and safety set out minimum requirements and fundamental principles, for managing the specific problems related to occupational risks, principle of prevention and risk assessment, as well as the responsibilities of employers and employees. A series of European guidelines aims to facilitate the implementation of European directives, including standards of related fields. The European Union Strategic Framework on Health and Safety at Work $2014-2020$ has pushed the Member States to review their national strategies in close consultation with relevant stakeholders including the social partners. Thus, national strategies must transfer and customize the European vision to the national culture and specifics, considering the European framework that acts as a common guide and reference. Romania has adopted several versions of the National Strategy for Health and Safety at Work and the last one is related to the $2018-2020$ period. Based on this document and the implementation plan associated the article will present a quantitative approach of the SWOT analysis. This research approach is meant to identify and characterize the new strategic direction that should be followed, together with a set of important aspect for the implementation plan up-date. The conclusions of this study will provide a scientific base for policy makers in the field of occupational health and safety.
\end{abstract}

\section{Introduction}

European directives related the occupational health and safety as: 89/391 EEC (framework directive), 89/654 EEC (workplaces), 89/655 EEC (work equipment), 89/656 EEC (personal protective equipment), 90/269 EEC (manual handling of loads) and 90/270 EEC (display screen equipment) set out minimum requirements and fundamental principles, for managing the specific problems related to occupational risks, principle of prevention and risk assessment, as well as the responsibilities of employers and employees. A series of European guidelines aims to facilitate the implementation of European directives, including standards of related fields. The European Union Strategic Framework on Health and Safety at Work 2014 - 2020 has pushed the Member States to review their national strategies in

* Corresponding author: nicoleta.neag@student.upt.ro 
close consultation with relevant stakeholders including the social partners. Thus, national strategies must transfer and customize the European vision to the national culture and specifics, considering the European framework that acts as a common guide and reference.

Romania has adopted several versions of the National Strategy for Health and Safety at Work and the last one is related to the 2018 - 2020 period (Decision no. 191/2018 of 4 April 2018) [1]. Based on this document and the implementation plan associated the article will present a quantitative approach of the SWOT analysis. This research approach is meant to identify and characterize the new strategic direction that should be followed, together with a set of important aspect for the implementation plan up-date. The conclusions of this study will provide a scientific base for policy makers in the field of occupational health and safety.

\section{Materials and method}

In order to develop the SWOT analysis of the Romanian OHS strategy, there will be presented some methodological aspects for the quantitative adopted approach.

\subsection{Preliminary resources for the SWOT analysis of the Romanian OSH strategy}

In Romania, on October 1, 2006, has been adopted and entered into force Law No $319 / 2006$, known as the Health and Safety Law that fully integrate and transfer the European Union framework directive 89/391/EEC to the national context specifics. According to this law, it lays down the General principles and the rights and obligations of employers and workers in order to ensure the health and safety conditions in the workplace as well as the measures to be taken by employers for this purpose. An essential component of sustainable development based on the integrated approach of the concepts of flexibility and security on the labor market is to promote investment in human resources. The legislative framework described by the Law No 319/2006 has been up-dated and modified in the following years to better fit to the dynamics of the economic context, as well as to the organizations' new working conditions and challenges.

The Romanian OSH strategy, named the Strategy on Health and Safety at Work, has been developed first in 2014, for the period of $2014-2020$, and then up-dated in 2018 (according to the Decision no. 191/2018 [1]) in accordance and by integrating the last measures required at the European Union (EU) level. The Romanian OSH strategic approach has been supported and developed by the Ministry of Labor and Social Justice, which is the competent authority in the OSH field at the national level. OSH strategy has considered and careful approach the future EU challenges as the occupational diseases, new and emerging risks, demographic changes (ageing workforce, migration), the legal framework (valid in 2018), and pay a special attention to the improved of the statistical tools and report methodologies on OSH.

\subsection{Methodological aspects for quantitative SWOT analysis}

SWOT analysis supposes that the organization will adopt a strategy direction to align the essential aspects of the internal and external environment. Therefore, the model is known in American literature as alignment model or the fit model [2]. Applying of a SWOT analysis in the case of an organization is done by asking and answering questions to generate meaningful information for each category or topics related to strengths, weaknesses, opportunities and threats to identify organization's competitive advantage. SWOT has been 
described as the tried-and-true tool of strategic analysis [2-3]. Strengths and weakness issues in the analysis are related to the organization internally-related issues, while opportunities and threats commonly focus on the external environment characteristics. Summarizing these core aspects of the SWOT analysis, the following statements have been made:

- Strengths are related to the characteristics of the organization, business or project that give it an advantage over others;

- Weaknesses refer to the characteristics of the organization, business that place the internal process or project at a disadvantage relative to others;

- Opportunities are associated with elements or aspects of the environment that the business or project could exploit to its advantage;

- Threats refer to elements in the environment that could cause troubles, difficulties and obstacles for the business or project.

SWOT analysis in the organizational strategy practice is beneficial because it helps decide whether an objective is achievable and therefore enables organizations to set realistic goals, objectives, and steps to further the social change or community development effort. In addition, it enables managers (assisted or not by external consultants) to take visions and produce practical and efficient outcomes that effect long-lasting developments and change, and support organizations for collect and organize meaningful information to maximize their potential, in terms of increasing their competitive advantage. Completing a SWOT analysis is a useful process regarding the consideration of key organizational priorities [2].

From the practical perspective, a quantitative approach of the SWOT analysis is associated with the definition and graphical representation of the strategic direction in a plan (Cartesian approach) defined by two dimensions:

- SW axis related to the organization, business or project internal factors (Ox axis);

- OT axis associated with the external factors that influence the organization, business or project on-going processes, activities (Oy axis).

There is associated with Ox, Oy axis of a chart with rectangular axes. A combination of internal factors and external factors can determine a strategic direction related to one of the four quadrants as shown in Table 1 (synthesis of the discussions from [2-3]).

Table 1. Qualitative matrix of strategic variants offered by SWOT analysis

\begin{tabular}{|c|c|c|}
\hline & S-Strengths & W-Weaknesses \\
\hline O-Opportunities & $\begin{array}{c}\text { OS Opportunity-Strength strategy, } \\
\text { type Max-Max } \\
\text { Use strengths to take advantage of } \\
\text { opportunities }\end{array}$ & $\begin{array}{c}\text { OW Opportunity-Weakness strategy, } \\
\text { type MIN-MAX } \\
\text { Overcome weaknesses by taking } \\
\text { advantage of opportunities }\end{array}$ \\
\hline T-Threats & $\begin{array}{c}\text { TS Threat-Strength strategy, type } \\
\text { MAX-MIN }\end{array}$ & $\begin{array}{c}\text { TW Threat-Weakness strategy, type } \\
\text { MIN-MIN } \\
\text { Use strengths to avoid threats }\end{array}$ \\
Minimize weakness and avoid threats \\
\hline
\end{tabular}

The quantitative approach for the SWOT analysis can be developed by following the next steps:

1. Listing the main internal factors ( $\mathrm{S}$ and $\mathrm{W}$ factors inventories);

2. Granting these factors weightings so that the sum of weights to be $1\left(K_{i j}\right)$;

3. Granting of scores on a scale with 0 as midpoint. Negative scores signify that the internal factor listed are weakness for the analyzed organization, business or project while the positive scores are related to the strengths;

4. Calculating total score as the sum of the products from the scores awarded $\left(p_{j}\right)$ and the weights of the factors considered $\left(n_{j}\right)$. The result represents the SW coordinates $(x)$, 
could be represented on the related axis (Ox). Relations for the above mention calculations are shown in the following formulas:

$$
\begin{array}{r}
p_{j}=\frac{\sum_{i=1}^{n} K_{i j}}{\sum_{j=1}^{m}\left(\sum_{i=1}^{n} K_{i j}\right)} \\
x=\sum_{j=1}^{m} p_{j} \times n_{j}
\end{array}
$$

5. Listing the main external factors ( $\mathrm{O}$ and $\mathrm{T}$ factors inventories);

6. Granting of weightings of these factors, so that the sum of the weights to be 1 ;

7. The granting of scores on a scale that has 0 as the midpoint. Negative scores signify that the external factor listed are threats for the analyzed organization, business or project while the positive scores are related to the opportunities;

8. Calculation of a total score is done in a similar way as in step four. Relation (3) shows the way in which OT coordinate ( $y$, related to the Oy axis) is calculated:

$$
y=\sum_{j=1}^{m} p_{j} \times n_{j}
$$

The calculated $x$ and $y$ together with their representation in the SW-OT plan will allow the determination of the strategic direction to be followed by the organization, business or the project. Furthermore, the position of the determinate point $(x, y)$ related to one of the four quadrants in the SW-OT plan, suggests the type of strategy that should be detailed together with the plan of measures that should be implemented. In addition, the analysis could be easy operationalized using the Excel application.

\section{SWOT analysis of the Romanian OSH strategy}

In the following chapter there will be presented the applied approach and the results of the quantitative SWOT analysis in the case of the Romanian OSH strategy. The study has been carried out in order to diagnose the condition of the strategy in the European Union legislative and normative context that has been documented based on the available information from the European Agency for Safety and Health at Work and the relevant studies $[4,5]$.

Following the already presented steps of the methodology, Table 2 shows the SW inventory (as suggested by the Romanian OSH strategy [1]) and Table 3 the OT one, developed based on the official information available for the European Union external environment context.

Table 2. The inventory of SW factors related to the OSH strategy in Romania.

\begin{tabular}{|l|l|}
\hline \multicolumn{1}{|c|}{ S-Strengths } & \multicolumn{1}{|c|}{ W-Weaknesses } \\
\hline $\begin{array}{l}\text { 1. Existence of national legislation harmonized } \\
\text { with the provisions of the EU legislative } \\
\text { framework in the field of OSH; }\end{array}$ & $\begin{array}{l}\text { 14. Deficiencies in respect of the } \\
\text { implementation of the legislation at the level } \\
\text { of employers, especially for SMSs, due to the }\end{array}$ \\
$\begin{array}{l}\text { 2. Existence of the legal framework for work } \\
\text { accidents and occupational diseases insurances; } ;\end{array}$ & $\begin{array}{l}\text { lack development of the OSH prevention } \\
\text { culture; }\end{array}$ \\
\hline
\end{tabular}




\begin{tabular}{|c|c|}
\hline S - Strengths & W - Weaknesses \\
\hline $\begin{array}{l}\text { the field of OSH and entities with } \\
\text { research/development, including specific } \\
\text { National Institute of research and development } \\
\text { in the field of OSH; } \\
\text { 4. Existing of an organization and functioning } \\
\text { of external services for prevention and } \\
\text { protection framework; } \\
\text { 5. Existence of minimum requirements for } \\
\text { training in the field of OSH; } \\
\text { 6. Campaigns and information activities in the } \\
\text { field OSH; } \\
\text { 7. Sectoral research and development plan of } \\
\text { micro and small enterprise ensuring financing } \\
\text { for the development of tools/guides/materials in } \\
\text { the field of OSH; } \\
\text { 8. Participation of the OSH stakeholders at } \\
\text { meetings and events organized at the European } \\
\text { level and international institutions; } \\
\text { 9. Increasing the number of medical } \\
\text { practitioners (related to } 2007 \text { ); } \\
\text { 10. Improved quality of medical services } \\
\text { determined that medical examinations are } \\
\text { carried out exclusively by occupational health } \\
\text { physicians; } \\
11 \text {. Occupational medicine doctors trained for } \\
\text { implementation of preventive programs; } \\
\text { 12. Existence of relevant professional } \\
\text { organizations active in the field of occupational } \\
\text { medicine; } \\
\text { 13. Exchange of experiences and good practices } \\
\text { in the implementing OSH legislation, in the } \\
\text { framework of the committee of labor inspection } \\
\text { senior and committee officers. }\end{array}$ & $\begin{array}{l}\text { OSH skills development (weak develop); } \\
\text { 16. OSH laws and regulations are not well } \\
\text { correlated with labor market dynamics; } \\
\text { 17. Insufficient cooperation with the social } \\
\text { partners; } \\
\text { 18. Insufficient information for the correct } \\
\text { approach to risk management related to new } \\
\text { and emerging risks; } \\
\text { 19. Insufficient number of OSH tools } \\
\text { necessary for an unified approach of the legal } \\
\text { provisions application to employers; } \\
\text { 20. Insufficient founding for impact studies } \\
\text { and analyses carried out by the specialized } \\
\text { research and development institutes; } \\
\text { 21. Employers' low level of awareness of } \\
\text { their responsibilities in the OSH area; } \\
\text { 22. Limited medical services, mostly for the } \\
\text { actions of health assessment for the } \\
\text { prevention programs and health promotion; } \\
\text { 23. Lack of diagnostic and underreporting of } \\
\text { the occupational diseases; } \\
\text { 24. Absence of effective tools in reporting } \\
\text { and monitoring of medical surveillance of } \\
\text { workers; } \\
\text { 25. Difficulties in collecting statistical data } \\
\text { and creation of databases on the level of } \\
\text { exposure, the number of workers exposed and } \\
\text { occupational diseases; } \\
\text { 26. Difficulties in management of } \\
\text { occupational medical activity; } \\
\text { 27. Insufficient number of occupational } \\
\text { medicine doctors at the directions of public } \\
\text { health. }\end{array}$ \\
\hline
\end{tabular}

Table 3. The inventory of OT factors related to the OSH context in Europe.

\begin{tabular}{|c|c|}
\hline O-Opportunities & T-Threats \\
\hline $\begin{array}{l}\text { 1. Improving the implementation record of } \\
\text { Member States, by enhancing the capacity of } \\
\text { micro and small enterprises to put in place } \\
\text { effective and efficient risk prevention } \\
\text { measures; } \\
\text { 2. Improving the prevention of work-related } \\
\text { diseases by tackling existing, new and } \\
\text { emerging risks; } \\
\text { 3. Tackling demographic change - the } \\
\text { working population in EU is ageing; } \\
\text { 4. Further consolidate national strategies; } \\
\text { 5. Facilitate compliance with OSH } \\
\text { legislation, particularly by micro and small } \\
\text { enterprises; } \\
\text { 6. Better enforcement of OSH legislation by } \\
\text { all Member States; } \\
\text { 7. Simplify existing legislation }\end{array}$ & $\begin{array}{l}\text { 16. Implementation of the EU strategy } \\
\text { continues to be a problem, especially for micro } \\
\text { and small enterprises which are having } \\
\text { difficulties as regards compliance with certain } \\
\text { regulatory requirements; } \\
\text { 17. There are gaps, as regards the impact on } \\
\text { individual enterprises at the local level, and } \\
\text { especially to micro and small enterprises; } \\
\text { 18. The involvement of other partners and the } \\
\text { social one at the national level, it was more } \\
\text { difficult to achieve; } \\
\text { 19. The collection of statistical data and the } \\
\text { development of monitoring tools are } \\
\text { insufficient; } \\
\text { 20. Even if the prevention measures are more } \\
\text { effective, health and safety at work in the EU } \\
\text { still requires further improvements; }\end{array}$ \\
\hline
\end{tabular}




\section{O-Opportunities}

8. Address the ageing of the workforce, emerging new risks, prevention of work-related and occupational diseases by all Member States;

9. Improve statistical data collection and develop the information base; efforts to address $\mathrm{OSH}$ and engage with international organizations;

11. Legislation has proven its value in providing the EU with a common body of definitions, standards, methods and preventive tools in the area of OSH;

12. Member States are encouraged to use the European Structural and Investment Funds to finance actions relating to $\mathrm{OSH}$;

13. Intensification of social dialogue; communication and information;

14. Synergies with other policy areas;

15. OSH strategic framework implementation.
10. Better coordinate EU and international

\section{T-Threats}

21. The general situation is still critical. Every year more than 4,000 workers die due to work accidents and more than 3 mil. workers are victims of serious work accidents leading to an absence from work of more than 3 days;

22. OSH Opinion/perception is still negative for a large percent of employees. $24.2 \%$ of workers consider that their health and safety is at risk because of their work, and $25 \%$ declared that work had a mainly negative effect on their health;

23. In addition to human suffering, the costs due to work-related sick are unacceptably high;

24. Costs for social security attributable to sickness or accidents are unacceptably high;

25. In order to further improve workers health and safety as requested by the Treaty the Commission should take sustained policy action in cooperation with the Member States; 26. When acting on OSH problems, due account should be taken of the costs to companies;

27. Compliance costs are also higher for micro and small enterprises in relative terms.

For each item from the SW and OT inventory there has been proceed the calculations related to the described methodology. The results are presented in the Tables 4 and 5 (extract from the calculations done using Excel application).

Table 4. Comparison of SW factors related to the OSH strategy in Romania (extract).

\begin{tabular}{|c|c|c|c|c|c|c|c|c|}
\hline $\mathbf{K}$ & 1 & 2 & 3 & $\cdots$ & 25 & 26 & 27 & \\
\hline 1 & $X$ & 0.5 & 0.5 & $\ldots$ & 0.5 & 0.5 & 1 & \\
\hline 2 & 0.5 & $X$ & 0.5 & $\cdots$ & 0.5 & 0.5 & 1 & \\
\hline 3 & 0.5 & 0.5 & $X$ & $\ldots$ & 0.5 & 0.5 & 1 & \\
\hline$\ldots$ & $\ldots$ & $\ldots$ & $\ldots$ & $\ldots$ & $\ldots$ & $\ldots$ & $\ldots$ & \\
\hline 25 & 0.5 & 0.5 & 0.5 & $\cdots$ & $\mathrm{X}$ & 0.5 & 1 & \\
\hline 26 & 0.5 & 0.5 & 0.5 & $\ldots$ & 0.5 & $X$ & 1 & \\
\hline 27 & 0 & 0 & 0 & $\ldots$ & 0 & 0 & $X$ & \\
\hline$\Sigma \mathbf{k}$ & 5 & 4.5 & 4.5 & $\cdots$ & 12.5 & 12.5 & 22.5 & 350 \\
\hline nj & 4 & 4 & 4 & $\ldots$ & -6 & -6 & -10 & \\
\hline pj & 0.0143 & 0.0129 & 0.0129 & $\ldots$ & 0.0357 & 0.0357 & 0.0643 & \\
\hline pj $x$ nj & 0.0571 & 0.0514 & 0.0514 & $\ldots$ & -0.2143 & -0.2143 & -0.6429 & -2.485 \\
\hline
\end{tabular}

The results of the SW coordinates that are related to the internal environment quantitative analysis, which is the case of Romanian OSH strategy are shown by the relations (4) and (5):

$$
p_{j}=\frac{\sum_{i=1}^{27} K_{i}}{350}
$$




$$
x=\sum_{i=1}^{27} p_{j} \times n_{j}=-2.134
$$

Table 5. Comparison of OT factors related to the OSH context in Europe (extract).

\begin{tabular}{|c|c|c|c|c|c|c|c|c|}
\hline $\mathbf{K}$ & 1 & 2 & 3 & $\ldots$ & 25 & 26 & 27 & \\
\hline 1 & $\mathrm{X}$ & 0.5 & 0.5 & $\cdots$ & 0.5 & 0.5 & 0.5 & \\
\hline 2 & 0.5 & $\mathrm{X}$ & 0.5 & $\ldots$ & 0.5 & 0.5 & 0.5 & \\
\hline 3 & 0.5 & 0,5 & $X$ & $\ldots$ & 0.5 & 0 & 0 & \\
\hline$\ldots$ & $\ldots$ & $\ldots$ & $\ldots$ & $\ldots$ & $\ldots$ & $\ldots$ & $\ldots$ & \\
\hline 25 & 0.5 & 0.5 & 0.5 & $\ldots$ & $X$ & 0.5 & 0.5 & \\
\hline 26 & 0.5 & 0.5 & 1 & $\cdots$ & 0.5 & $X$ & 0.5 & \\
\hline 27 & 0.5 & 0.5 & 1 & $\cdots$ & 0.5 & 0,5 & $X$ & \\
\hline$\Sigma \mathbf{k}$ & 6.5 & 15 & 14.5 & $\cdots$ & 14 & 13.5 & 13.5 & 343 \\
\hline $\mathbf{n j}$ & 6 & 9 & 9 & $\ldots$ & -8 & -8 & -8 & \\
\hline pj & 0.0189 & 0.0437 & 0.04227 & $\cdots$ & 0.0408 & 0.0393 & 0.0393 & \\
\hline pj $x \mathbf{n j}$ & 0.1137 & 0.3935 & 0.38047 & $\ldots$ & -0.3265 & -0.3149 & -0.3149 & 2.523 \\
\hline
\end{tabular}

The results of the quantitative analysis according to the OT external environment inventory list, which is the case of the European Union implementation of OSH strategy, by considering the global effort of the Members States (as suggested by $[4,5]$ ) are shown by the relations (6) and (7):

$$
\begin{gathered}
p_{j}=\frac{\sum_{i=1}^{27} K_{i}}{343} \\
y=\sum_{i=1}^{27} p_{j} \times n_{j}=+2.523
\end{gathered}
$$

Based on the results of the SWOT quantitative analysis shown by the relation (5) and (7) there has been represented the strategic direction that should be followed for the up-date of the measures plan related with the future implementation years (Fig. 1).

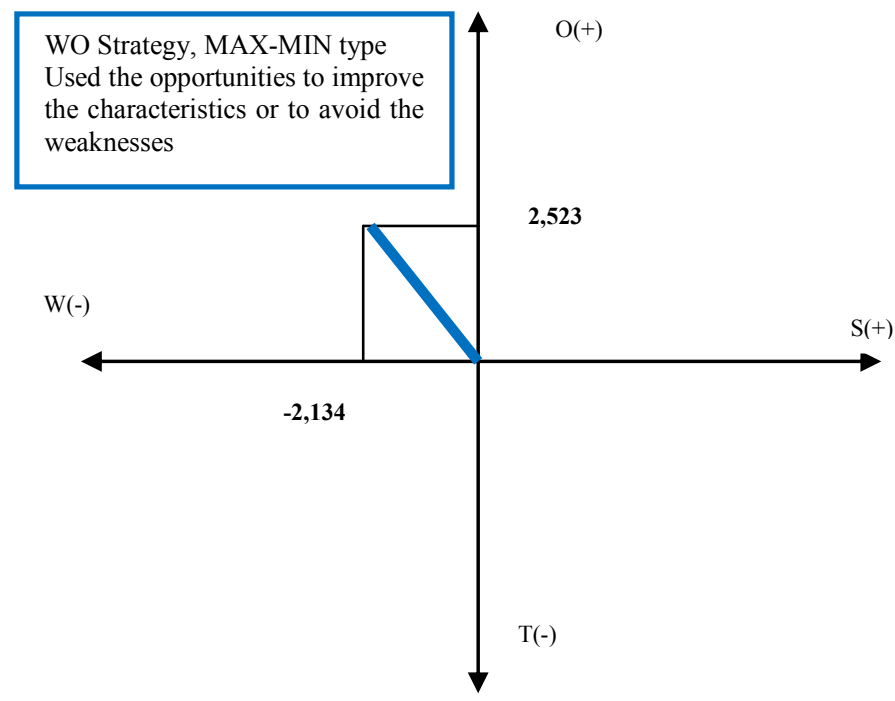

Fig. 1. The strategic direction to be followed with the support of the measures plan (SWOT profile). 


\section{Conclusions of the study}

The application of a quantitative SWOT analysis in the case of Romania OSH strategy has been done using the support opinions and perception of a group of $24 \mathrm{OSH}$ specialists, mainly from the West Region of the country (academics, work inspectors, human resources specialists, trainers and consultant, managers of SMEs, responsible of OSH in multinational companies). Their contributions were mainly in the 2, 3,6 and 7 stages of the proposed methodological approach, when the listed SWOT factors must be compared and granted to get a realistic hierarchy and to allow the strategic profile elaboration. For these purposes several interviews, discussions and, one focus group with 12 specialists have been organized. Thus, the aspects related to subjective opinions of the researcher has been minimized.

The SWOT profile represented in Fig. 1 shows that for the next plan of measures, a MAX-MIN type strategy and behavior should be adopted. The related strategy document (the Decision no. 191/2018) is weak in terms of considering the actual problems, challenges of OSH (mentioned in the last analysis at the European level [6]) and the implementation plan needs to be adapted consequently. In addition, according to the discussions and interview results with the specialists involved in the research, there are numerous contradictions and negative aspects, regarding to the legislative framework in Romania that should be adjust rapidly. This could facilitate the inspection and evaluation/control processes related to OSH, activities carried out by special authorities. An important aspect of the future strategic approach is the need of an intensive work for changing attitudes and behavior of employers and employees in nurturing an effective safety culture combined with a preventive attitude in the field of occupational risk management. These are few aspects that can contribute to the occupational well-being increasing [7]. In addition, all these aspects can be supported by the favorable conditions of the external environment.

\section{References}

1. Romanian Government, Decision no. 191/ 4 April 2018, available at: http://www.mmuncii.ro/j33/images/Documente/Legislatie/HG191-2018.pdf (Access on March 3, 2019)

2. T. H. Davenport, M. Leibold, S. C. Voelpel, Strategic management in the innovation economy: Strategic approaches and tools for dynamic innovation capabilities, John Wiley \& Sons, (2007)

3. E. Gürel, M. Tat, SWOT analysis: a theoretical review, Journal of International Social Research, 10(51) (2017)

4. E. Schmitz-Felten, L. Lieck, National Strategies in the field of Occupational Safety and Health in the EU, Report published by the European Agency for Safety and Health at Work, EU-OSHA, (2018), available at: https:/osha.europa.eu/en/safety-and-health-legislation/osh-strategies (Access on March 6, 2019)

5. EU-OSH, European opinion poll on occupational safety and health (2013), available at: https://osha.europa.eu/ro/surveys-and-statistics-osh/european-opinion-polls-safety-and-healthwork/european-opinion-poll-occupational-safety-and-health-2013 (Access on March 6, 2019)

6. E. Schmitz-Felten, L. Lieck, National Strategies in the field of Occupational Safety and Health in the EU, Report published by the European Agency for Safety and Health at Work, EU-OSHA, (2018), available at: https://osha.europa.eu/en/safety-and-health-legislation/osh-strategies (Access on March 6, 2019)

7. G. Rusu-Zagar, C. Rusu-Zagar, The legal system for occupational safety and health in Romania occupational safety and health within the European strategy, Euromentor Journal, 6(3), 90 (2015) 